\title{
Globe
}

Revue internationale d'études québécoises

\section{Sherry Simon : Hybridité culturelle, Montréal, L'Île de la tortue, coll. « Une encyclopédie vivante ", 1999}

\section{Daniel Chartier}

Volume 4, numéro 1, 2001

URI : https://id.erudit.org/iderudit/1000612ar

DOI : https://doi.org/10.7202/1000612ar

Aller au sommaire du numéro

Éditeur(s)

Globe, Revue internationale d'études québécoises

ISSN

1481-5869 (imprimé)

1923-8231 (numérique)

Découvrir la revue

Citer ce compte rendu

Chartier, D. (2001). Compte rendu de [Sherry Simon : Hybridité culturelle, Montréal, L'île de la tortue, coll. « Une encyclopédie vivante », 1999]. Globe, 4(1), 163-164. https://doi.org/10.7202/1000612ar d'utilisation que vous pouvez consulter en ligne.

https://apropos.erudit.org/fr/usagers/politique-dutilisation/ 
envers le nationalisme québécois que ne l'est Garth Stevenson, ce sera l'heure "to say goodbye", pour citer Reed Scowen. Une chose est certaine, l'époque du consociationalisme entre élites anglophone et francophone à l'intérieur du Québec est bel et bien révolue. Le livre de Garth Stevenson en dresse un bilan définitif. Conseillons-le donc à tous ceux qui s'intéressent de près ou de loin au sort de cette minorité qui fut et demeure hautement névralgique dans l'histoire québécoise.

\section{Philip Resnick \\ Université de la Colombie-Britannique (Canada)}

\section{Sherry Simon}

Hybridité culturelle

Montréal, L'île de la tortue, coll. "Une encyclopédie vivante ", 1999.

Troisième titre d'une jeune collection encyclopédique publiée chez un nouvel éditeur montréalais, L'île de la tortue, l' Hybridité culturelle de Sherry Simon, professeure à l'Université Concordia, se présente comme une synthèse et un point de vue personnel sur la question de l'hybridité, définie comme un passage plutôt qu'un état culturel. "L'hybridité culturelle rend compte de faits qui marquent le moment présent, écrit-elle ; elle décrit des réalités socio-démographiques, des identités, des pratiques artistiques " (p. 27).

Simon, à qui l'on doit Le Trafic des langues (1994) et qui a déjà beaucoup travaillé sur les questions des minorités, de l'exil, de l'altérité, de la traduction, de l'appartenance et de l'identitaire, offre ici un court essai qui esquisse quelques analyses et pose les bases théoriques de l'hybridité culturelle, un sujet sur lequel, "malgré sa popularité dans le vocabulaire critique des sciences sociales anglo-américaines, il existe peu d'ouvrages * (p. 58).

En s'attardant aux formes et pratiques de l'hybride dans le quartier montréalais Mile-End, "un espace marginal où les migrants de tout 
genre se reconnaissent "(p. 21) et en présentant quelques auteurs d'écritures hybrides, tels que Klein, Laferrière et Rushdie, l'auteure arrive à distinguer le concept d'hybridité des termes qui lui sont parents : le multiculturalisme, le syncrétisme, la créolité et le métissage.

La collection "Les élémentaires. Une encyclopédie vivante " compte quelques titres, notamment sur le cinéma de Hong Kong, l'économie sociale et l'anarchisme. Elle se veut une "encyclopédie générale qui communique la connaissance sous le signe de la ferveur et de la passion en accordant une place prépondérante aux auteurs". En cherchant à "dresser le portrait de la société québécoise qui, prise dans son ensemble est une véritable encyclopédie vivante ", l'éditeur relève le défi de concilier la concision, la synthèse et la subjectivité, ce qui n'est pas simple.

Aussi, la teneur de la collection impose un certain ton, qui n'est pas sans susciter le caractère enthousiaste de l'écriture, avec le risque certain de taire les antithèses au profit de l'engagement. Simon arrive toutefois à esquiver le pamphlet et à nous convaincre de la pertinence du concept d'hybridité, tout en expliquant dans une langue simple, dépouillée et sobre la nécessité de prendre en compte le multiple transitoire dans notre compréhension du monde contemporain, et notamment du Québec d'aujourd'hui.

Daniel Chartier Université du Québec à Montréal

\section{Fernande Roy}

Histoire de la librairie au Québec.

Montréal, Leméac, 2000.

Il est indéniable que la librairie est un territoire négligé de l'histoire du livre au Québec. Pourtant, elle constitue un lien essentiel entre les éditeurs et les lecteurs. Contrairement à l'édition, qui a été largement étudiée depuis quelques décennies, la librairie n’a donné lieu qu'à 